\title{
Accelerated Weathering Properties of Hemp Fibre Composites
}

\author{
Asim Shahzad \\ Materials Research Centre, School of Engineering, Swansea University, Swansea, UK \\ Email: mr asim_shahzad@yahoo.com
}

Received 4 April 2014; revised 10 May 2014; accepted 18 June 2014

Copyright (C) 2014 by authors and OALib.

This work is licensed under the Creative Commons Attribution International License (CC BY). http://creativecommons.org/licenses/by/4.0/

(c) (i) Open Access

\begin{abstract}
Properties of hemp fibre reinforced unsaturated polyester composites following exposure to accelerated weathering conditions have been studied. Exposure to ultraviolet (UV) radiation and UV radiation plus condensation resulted in immediate loss in weight which stabilised following prolonged exposure times. The same exposure led to initial decline in tensile properties of hemp fibre composites, but the decline in properties also stabilised following prolonged exposure and these materials seemed to perform fairly well in these conditions. The decline in strength and modulus was quite similar, unlike immersion in water where the reduction in modulus was more pronounced than the reduction in strength. Discolouring of composites following exposure to these conditions was identified as an issue with these composites.
\end{abstract}

\section{Keywords}

\section{Hemp, Accelerated Weathering Testing, Tensile Properties, Weight Loss}

Subject Areas: Composite Material, Material Experiment

\section{Introduction}

One drawback of using natural fibre composites in outdoor applications is their poor weathering properties. Natural fibre composites are finding increasing applications (siding, windows, decks, roofs, etc.) where they are exposed to weathering agents, which can cause changes in the microstructure and the chemical composition of these composites. These changes in turn can modify properties such as strength, modulus, impact resistance and fatigue behavior, which can have adverse effects on the service life of these composites. Therefore for long service life, the weathering phenomenon and how its effects can be mitigated must be understood. The two main sources of natural weathering are UV radiation and moisture. Natural fibers are not only good absorbers of 
moisture but they are also susceptible to UV radiation. Natural fibres are susceptible to environmental degradation because of their structure. Photochemical degradation by UV light occurs primarily in lignin which is also responsible for colour change [1]. Amorphous cellulose and hemicellulose are mostly responsible for the high water uptake of natural fibers, since they contain numerous easily accessible hydroxyl groups which give a high level of hydrophilic character to fibers.

Although UV light makes up only about 5\% of sunlight, it is responsible for most of the sunlight damage to the materials, especially polymers, exposed outdoors. This is because photochemical effectiveness of light increases with decreasing wavelength. The energy of photons of UV light is sufficient to rupture the bonds within polymer molecules. This rupture causes changes in molecular weight, formation of cross-links, and reaction with oxygen. These structural changes lead to gross physical changes such as chalking, cracking, surface embrittlement, discolouring and loss of tensile and impact strength [2].

In one study on the effect of weathering on polyester resin, the resin was exposed to actinic rays in a twin arc fadeometer [3]. An exposure of 400 - 700 hours was considered equivalent to one year of outdoor exposure. Initially there was no visible change after several hundred hours of exposure. Then the yellowing of the samples suddenly became noticeable. The tensile strength of the resin deteriorated from $66 \mathrm{MPa}$ to $47 \mathrm{MPa}$ after 2400 hours of exposure. Similarly the flexural strength deteriorated from 90 MPa to $82 \mathrm{MPa}$ after same exposure period.

To simulate the physical damage caused by sunlight it is not necessary to reproduce the entire spectrum of sunlight. In many cases it is only necessary to simulate the short wavelength. To overcome the problem of UV light, ultraviolet absorbers, such as carbon black or aromatic ketones, are added to polymers.

The amount of moisture absorbed by the polymer matrix composite depends on the matrix type, exposure time, component geometry, relative humidity, temperature, and exposure conditions. Typical consequences of exposure of composite materials to these environments are: plasticisation of matrix, resulting in reduction in glass transition temperature and usable range, changes in dimensions and fibre/matrix debonding due to matrix and fibre swelling, enhanced creep and stress relaxation, resulting in increased ductility, change in coefficient of expansion, reduction in ultimate strength and stiffness, matrix cracking, and chain scission [4].

In case of natural fibre reinforced composites, additional problems are encountered because of hydrophilic nature of natural fibres. The moisture content of natural fibres can vary between $5 \%$ and $10 \%$. This can lead to dimensional variations in composites and also affects mechanical properties of composites. It can cause fibres to swell and ultimately rot through attack by fungi. A possible solution is to improve fibre-matrix interface by using compatibilizers and adhesion promoters. With better adhesion, the moisture sensitivity is usually reduced [5]. Also surface treatments of fibres with silanes can make the fibres more hydrophobic.

The study of weathering properties of natural fibre composites is a new and growing field. The use of accelerated weathering testing is a preferred method for this purpose whereby the outdoor exposure conditions are simulated in laboratory in controlled atmosphere and in accelerated conditions which can reproduce the damage to the material in few days or weeks that actually occurs over months or years of outdoor exposure.

A number of studies ([6]-[10]) have recently been carried out which have examined the effects of accelerated weathering on the properties of natural fibre composites. Generally, all types of natural fibre composites show fading of colour and reduction in mechanical properties following exposure to natural and accelerated weathering conditions. The use of coupling agents, fibre surface treatments, ultraviolet absorbers (UVAs) and pigments to improve the weathering resistance has been reported to have positive effects on composites.

\section{Experimental}

Samples of short, randomly oriented hemp fibre reinforced unsaturated polyester composites were made by using hand lay-up and compression mounding techniques. A close-up of hemp fibre mat used is shown in Figure 1. The average fibre weight fraction was 55\%. Samples of nominal dimensions of $120 \times 20 \times 2.5 \mathrm{~mm}$ were used for this study by using QUV Accelerated Weathering Tester as shown in Figure 2. The testing was conducted to BS EN ISO 4892-1: 2001, Plastics-methods of exposure to laboratory light sources-Part 1: general guidance, and BS EN ISO 4892-3: 2006, methods of exposure to laboratory light sources-Part 3: flourescent UV lamps. The materials used in outdoor applications are exposed to alternating cycles of UV light (daytime) and wetness because of dew (night time). The tester had the facility of simulating both conditions in the cycle and both conditions occurred separately in the machine just as they do in natural weathering. Each cycle consisted of exposure of eight hours of UV light followed by four hours of condensation. The tester was also used to expose the 


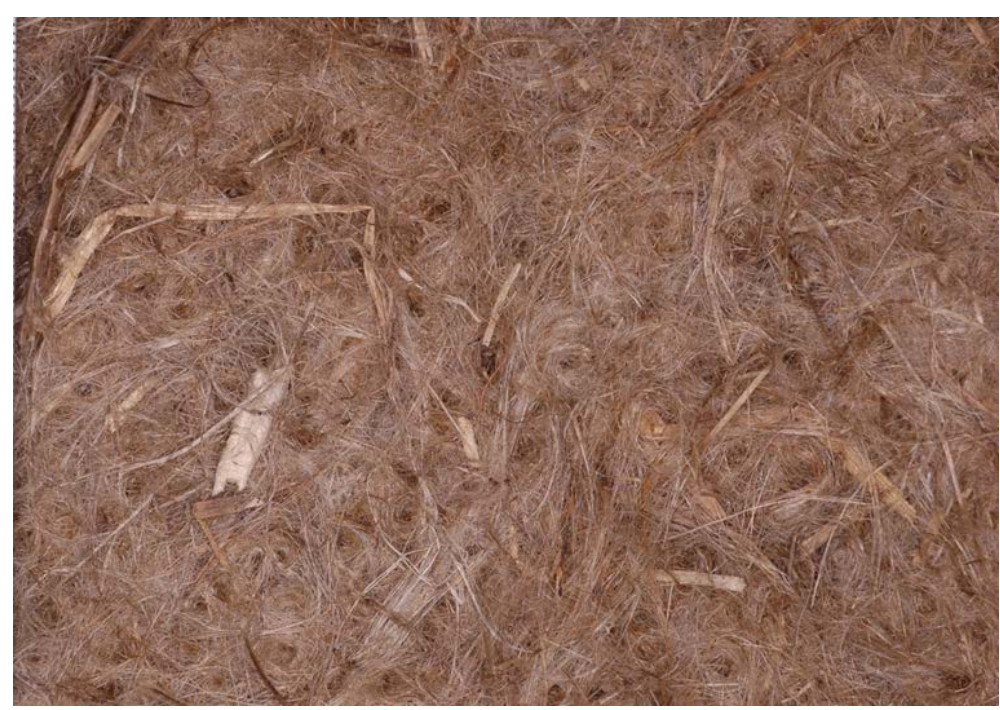

Figure 1. Hemp fibre mat.

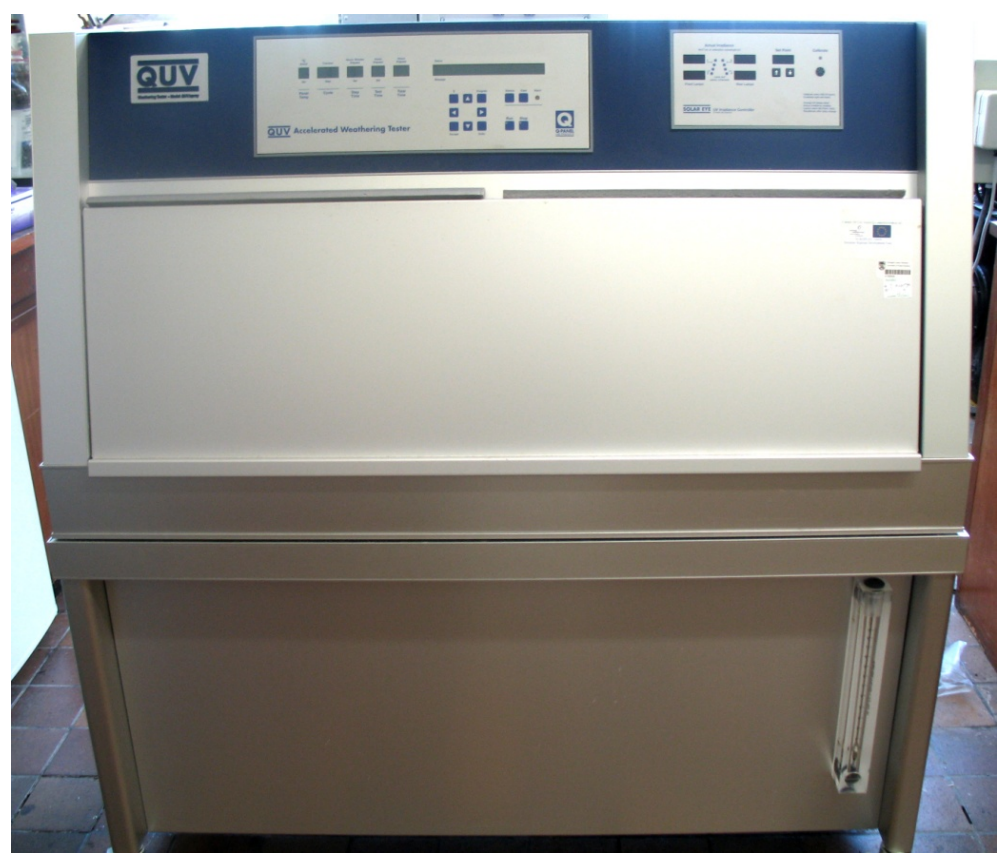

Figure 2. QUV accelerated weathering testing machine.

material to constant UV light. The samples were weighed and tested for tensile properties following pre-determined intervals of exposure to these conditions. All tensile tests were performed to BS EN ISO 527: 1996, plastics-determination of tensile properties, parts 1 and 4, using Hounsfield universal testing machine. A mechanical extensometer PS25C-0118 with gauge length of $25 \mathrm{~mm}$ was used to measure the strain in the samples during tensile tests.

\section{Results and Discussion}

\subsection{Weight Loss}

The effect of UV radiation only and UV radiation plus condensation on weight of these composites is shown in Figure 3. It was observed that the composites started to lose weight soon after exposure to these conditions. The increase in weight loss for UV exposed composites was greater than for UV plus condensation exposed compo- 


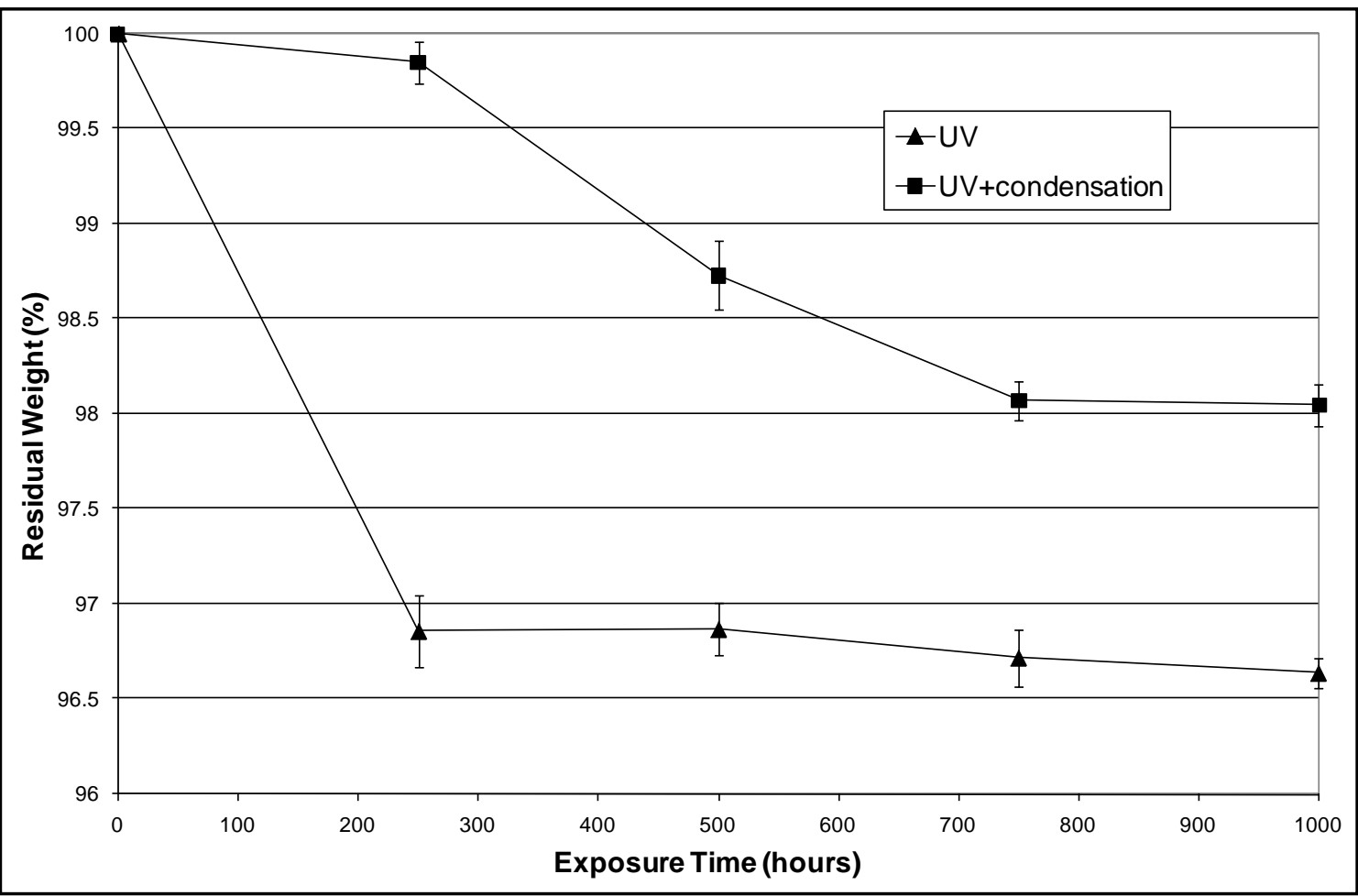

Figure 3. Weight loss of composites following exposure to UV and UV plus condensation cycles.

sites. Whereas UV exposed composites lost nearly 3.2\% of their original weight following 250 hours of exposure, UV plus condensation exposed composites lost only about $0.2 \%$ of their original weight following same exposure time. It has been shown that when unsaturated polyester resins are heated, the polymer chain begins to dissociate chemically and that polyesters have maximum photochemical sensitivity at wavelength of $325 \mathrm{~nm}$ [11]. Since the UV radiation used in this study had a wavelength of $340 \mathrm{~nm}$, it is expected that this resulted in degradation of the upper polyester layer of the composites resulting in loss of weight. This degradation is a manifestation of chain scission and breaking of bonds between polymer molecules following exposure to UV radiation. However following increased exposure times, as the UV radiation interacted with the hemp fibres, the fibres offered more resistance to UV radiation. This resulted in reduced degradation of the samples for exposure time of greater than 250 hours. Further exposure of the sample to UV light did not result in any increased loss in weight up to 1000 hours of exposure time. However for composites exposed to UV plus condensation conditions, the loss in weight due to UV radiation was compensated by increase in weight due to moisture absorption during the condensation cycle. Therefore the loss in weight for composites exposed to UV plus condensation was considerably less than that for UV radiation only. The weight loss stabilised to a value of about $1.9 \%$ following exposure of 700 hours.

\subsection{Tensile Properties}

The effects of UV radiation and condensation on tensile properties of the composites are shown in Figure 4, Figure 5. The exposure to UV light and condensation leads to some loss in tensile strength initially but prolonged exposure to these conditions leads to some recovery in strength and does not lead to any further decline in tensile strength. The maximum reduction in strength is about $40 \%$ following exposure time of 500 hours. Following 1000 hours of exposure, the decline in strength is about $20 \%$ of intrinsic strength.

The decline in tensile strength is more gradual for composites exposed to UV radiation only but stabilises after about 450 hours of exposure. After 1000 hours of exposure to UV light, the composites lost approximately $30 \%$ of their intrinsic tensile strength. Compared to this, the composites lost only $10 \%$ of their strength following immersion in water for the same time period. A detailed analysis of the effects of water immersion on mechanical properties of hemp fibre/polyester composites has been presented in another paper [12]. Thus UV light 


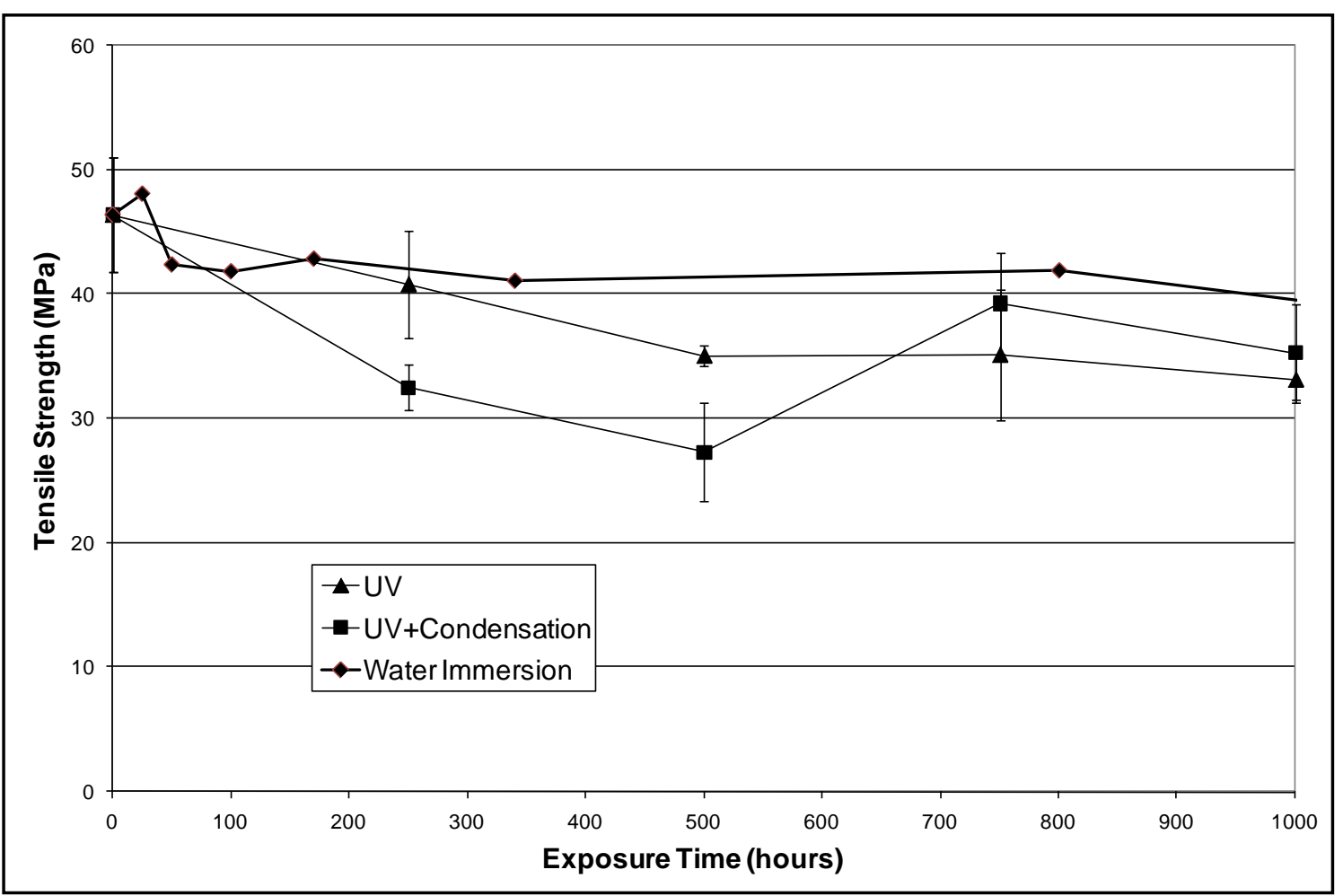

Figure 4. Effect of UV and UV plus condensation conditions on tensile strength of composites.

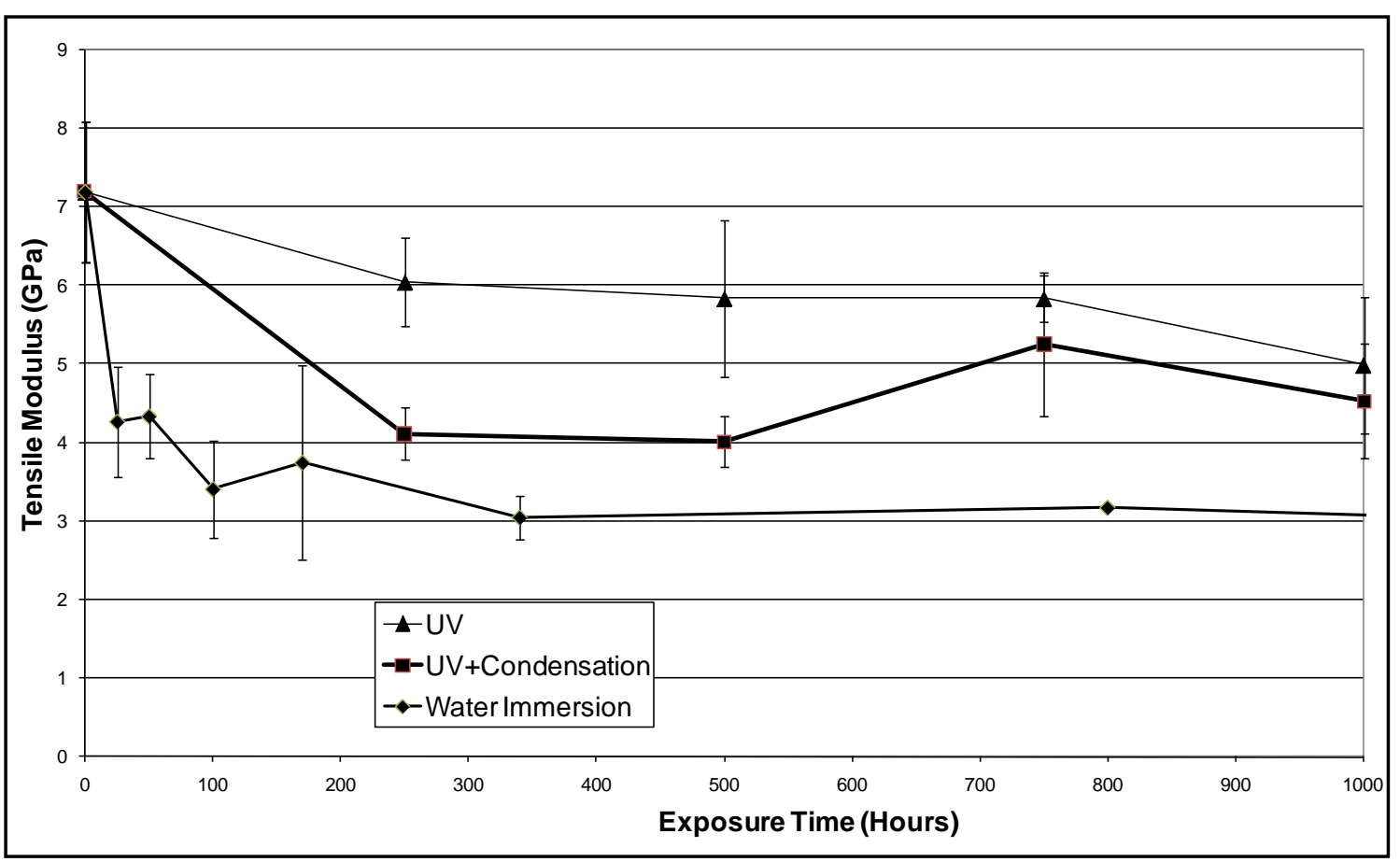

Figure 5. Effect of UV and UV plus condensation conditions on tensile modulus of composites.

results in greater degradation of tensile strength of composites than water.

For composites exposed to UV radiation plus condensation the decline in modulus seems to follow the same pattern as for decline in strength. The decline in modulus is non-uniform and after initial decline seems to re- 
cover for longer exposure times. The maximum decline is modulus is about $40 \%$ following exposure of 500 hours. After 1000 hours of exposure to UV radiation plus condensation, the composites lost almost 30\% of their intrinsic tensile modulus. The reduction in tensile modulus is more gradual for composites exposed to UV radiation only. After 1000 hours of exposure to UV radiation, the composites lost approximately $30 \%$ of their intrinsic modulus. However the loss in modulus is less for composites exposed to UV and UV plus condensation conditions compared to immersion in water. This is to be expected since the diffusion of water into the composites affects the bulk properties of the material, plasticising the polyester matrix and fibres. UV and condensation mostly affect the surface properties of the material only, thus having less effect on bulk properties of the material. Hence the greater reduction in modulus for composites immersed in water.

The effect of UV radiation and condensation on strain to failure of the composites is shown in Figure 6. The strain to failure does not seem to have been affected very much by exposure to these conditions and stays close to the non-exposed value of $1 \%$. However the strain to failure of composites immersed in water is considerably higher which can again be explained by the fact that the diffusion of water results in plasticisation of polyester resin and fibres, resulting in increase in strain to failure. UV and condensation affect the surface properties and hence the strain to failure is not affected.

The exposure of composites to UV and condensation did not affect their fracture mode which was completely brittle as for non-exposed composites which was in agreement with the similar strain to failure values for both cases. Figure 7 shows the comparison of stress-strain graphs of composites following exposure to both kinds of environments for 1000 hours with unexposed and water-immersed composites. The figure shows that the mechanical behaviour of the composites following exposure to weathering conditions did not change and the shape of the curve was found to be similar to that for unexposed composites, with a "knee" forming on the curve which is a characteristic of short fibre composites.

\subsection{Appearance}

One notable effect these conditions had was on the colour of these composites. The UV light can result in considerable yellowing of synthetic fibre composites also. The colour of these composites started to change from darkish brown to greyish brown. After 1000 hours of exposure it had changed to whitish brown as shown in Figure 8(a) and Figure 8(b). In each case, the top figure shows the hemp fibre sample without exposure to

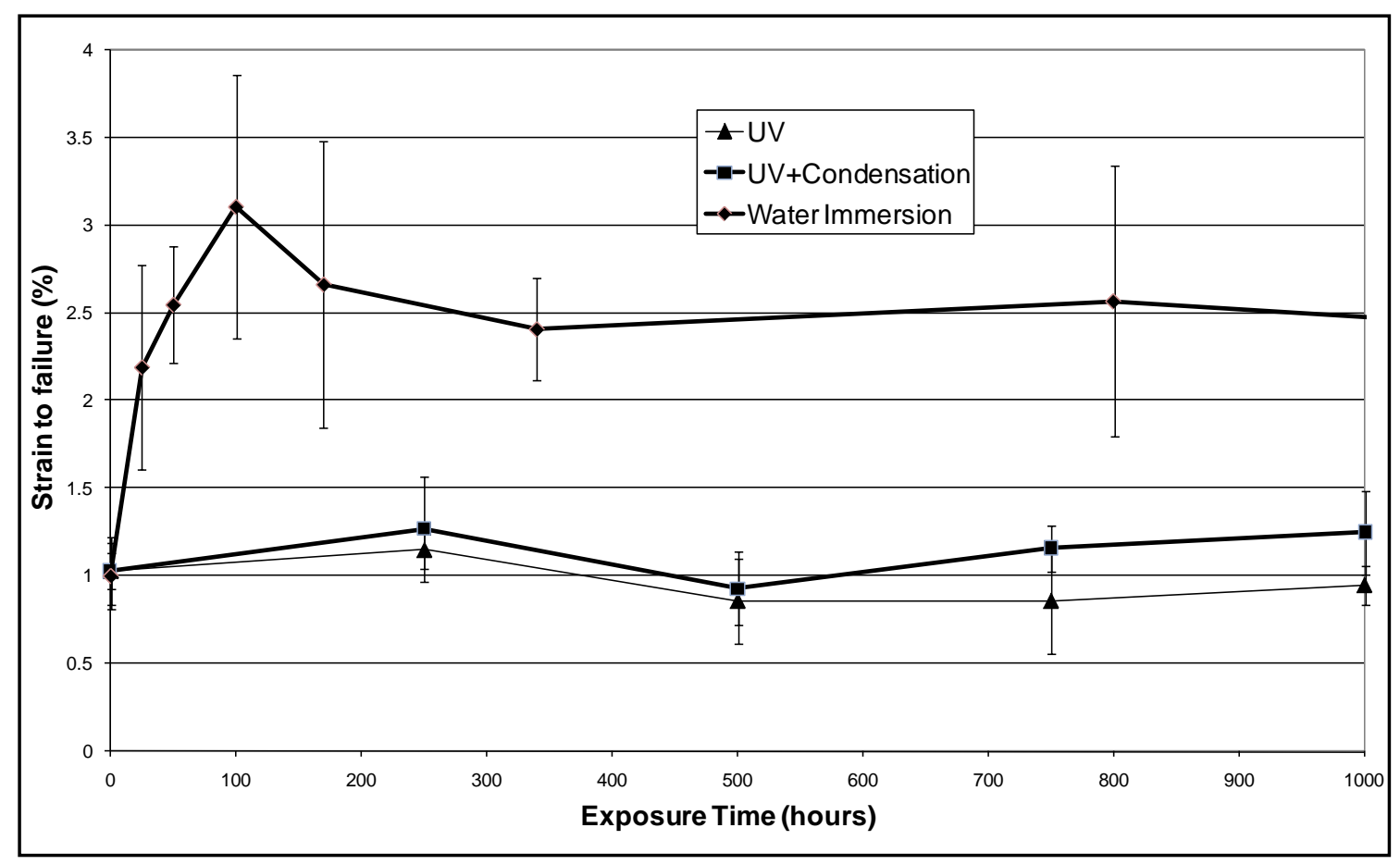

Figure 6. Effect of UV light and condensation on strain to failure of composites. 


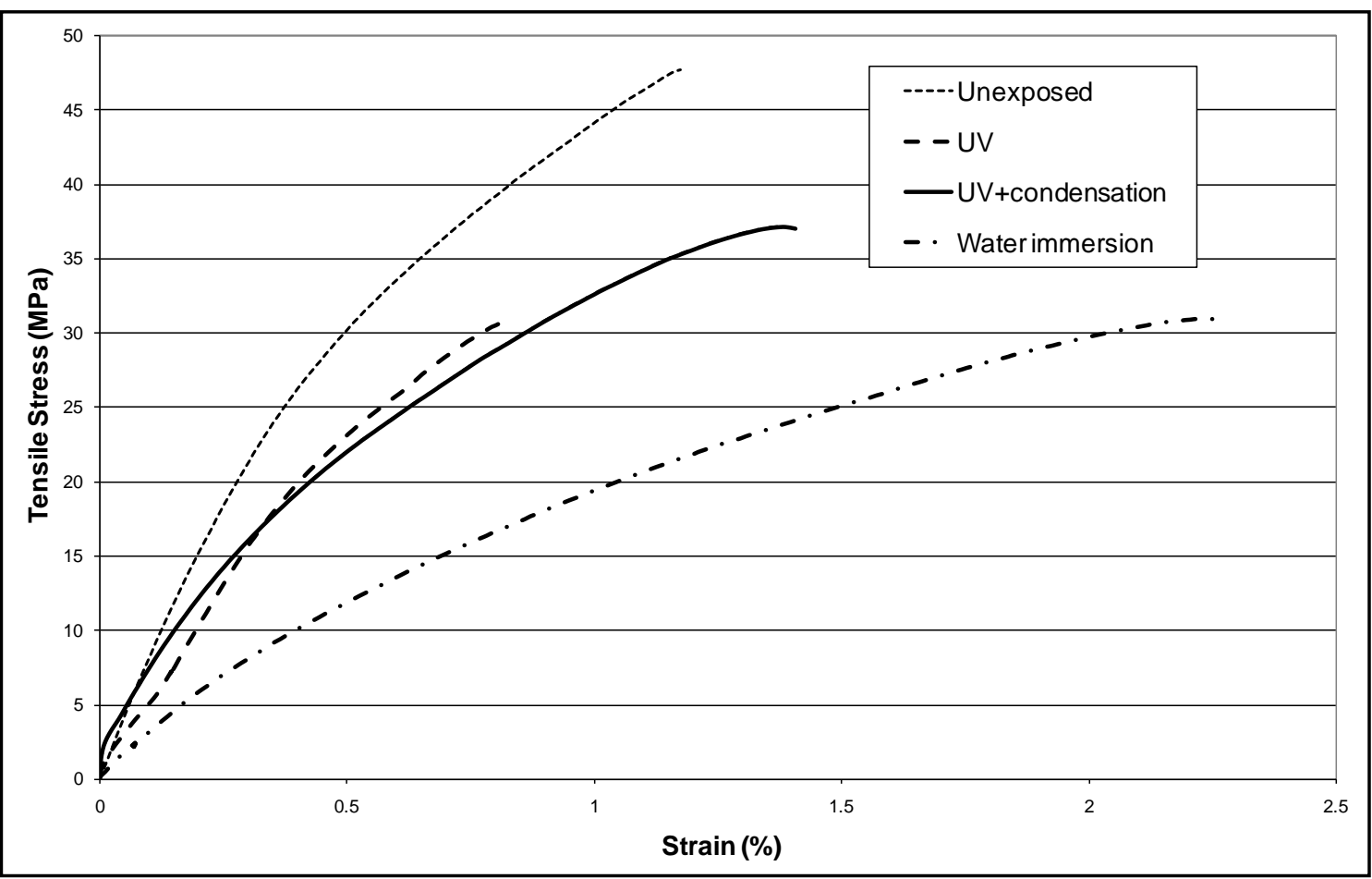

Figure 7. Comparison of stress-strain graphs of composites following exposure to UV and UV plus condensation for 1000 hours with unexposed and water-immersed composites.

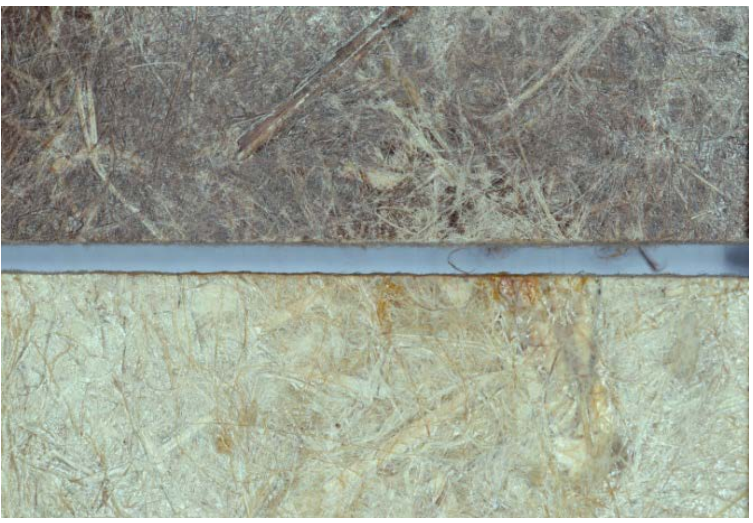

(a)

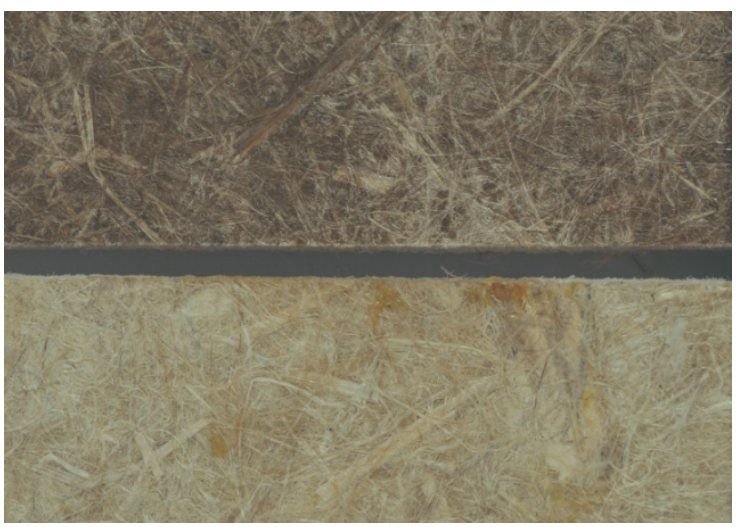

(b)

Figure 8. Discolouring and yellowness of the surface of composites following exposure of 1000 hours to (a) UV radiation and condensation, and (b) UV radiation.

weathering conditions. The reaction of water, oxygen and UV radiation within the organic matter in the composites promote the change of colour. Mehta et al. [13] studied the effect of accelerated weathering (UV + condensation + water spray) on colour change of natural fibre reinforced polyester composites by using reflectometer. The composites changed colour from greenish brown to white and the change in colour was more pronounced for hemp fibre composites than flax and big blue stem grass composites. Hence the interaction of hemp fibres with UV light and water can be considered to be the main reason for change in colour.

It has also been shown [14] that the exposure of polyester to accelerated outdoor weathering can result in change in its colour, measured by yellowness index. Thus both polyester resin and hemp fibres are expected to contribute to yellowness of the material. The discolouring and yellowness of the surface was more pronounced for composites exposed to UV radiation plus condensation because the moisture also contributed to the discolouring, which was also observed for composites immersed in distilled water. This fading of colour can have 
important aesthetic implications when these composites are to be used in outdoor applications. Some sort of coating, paint or UV absorbing additives can be used on these composites to stop the fading effect.

\section{Conclusions}

Exposing hemp fibre composites to accelerated weathering conditions of UV light and UV light plus condensation resulted in immediate loss in weight which stabilised for prolonged exposure times. Following exposure of 1000 hours, the loss in weight was about 3.2\% for composites exposed to UV light and about $1.9 \%$ for composites exposed to UV light plus condensation. Chemical dissociation of polyester resin due to exposure to UV light was considered to be the major reason for this loss in weight.

Exposure to the same conditions led to initial decline in tensile properties of hemp fibre composites, but the decline in properties did not increase after prolonged exposure. Following exposure of 1000 hours, the reduction in strength was $30 \%$ for UV exposed composites and 30\% for UV plus condensation exposed composites. The reduction in modulus was $30 \%$ for both UV exposed and UV plus condensation exposed composites. The reduction in strength and modulus of composites was quite similar, unlike immersion in water where the reduction in modulus was more pronounced than the reduction in strength. Discolouring of composites following exposure to these conditions was also identified as an issue with these composites.

\section{References}

[1] Mohanty, A.K., Misra, M. and Hinrichsen, G. (2000) Biofibres, Biodegradable Polymers and Biocomposites: An Overview. Macromolecular Materials and Engineering, 276-277, 1-24. http://dx.doi.org/10.1002/(SICI)1439-2054(20000301)276:1<1::AID-MAME1>3.0.CO;2-W

[2] Trojan, F. (1990) Engineering Materials and Their Applications. 4th Edition, Houghton Mifflin Company, Boston.

[3] Rubin, M. (1969) Polyester Resins. In: Lubin, G., Ed., Handbook of Fibreglass and Advanced Plastics Composites, Van Nostrand Reinhold Co., New York.

[4] Pritchard, G. (2000) Environmental Testing of Organic Matrix Composites. In: Hodgkinson, M.J., Ed., Mechanical Testing of Advanced Fibre Composites, Woodhead Publishing Limited, Cambridge.

[5] Schloesser, T.P. (2004) Natural Fiber Reinforced Automotive Parts. In: Wallenberger, F.T. and Weston, N., Eds., Natural Fibers, Plastics and Composites, Kulwer Academic Publishers, Boston. http://dx.doi.org/10.1007/978-1-4419-9050-1_15

[6] Zou, P., Xiong, H. and Tang, S. (2009) Natural Weathering of Rape Straw Flour (RSF)/HDPE and Nano-SiO $/ 2$ RSF/ HDPE Composites. Carbohydrate Polymers, 73, 378-383. http://dx.doi.org/10.1016/j.carbpol.2007.12.002

[7] Fabiyi, J.S. and McDonald, A.G. (2010) Effect of Wood Species on Property and Weathering Performance of Wood Plastic Composites. Composites Part A, 41, 1434-1440. http://dx.doi.org/10.1016/j.compositesa.2010.06.004

[8] Stark, N.M. and Matuana, L.M. (2006) Influence of Photostabilizers on Wood Flour-HDPE Composites Exposed to Xenon-Arc Radiation with and without Water Spray. Polymer Degradation and Stability, 91, 3048-3056. http://dx.doi.org/10.1016/j.polymdegradstab.2006.08.003

[9] Du, H., Wang, W., Wang, Q., Sui, S., Zhang, Z. and Zhang, Y. (2010) Effects of Pigments on the Ultraviolet Degradation of Wood Flour/HDPE Composites. Journal of Applied Polymer Science, 118, 1068-1076.

[10] Butylina, S., Hyvärinen, M. and Kärki, T. (2012) A Study of Surface Changes of Wood-Polypropylene Composites as the Result of Exterior Weathering. Polymer Degradation and Stability, 97, 337-345. http://dx.doi.org/10.1016/j.polymdegradstab.2011.12.014

[11] Gauthier, M.M. (1995) Engineered Materials Handbook. ASTM International, New York.

[12] Shahzad, A. (2011) Effects of Water Absorption on Mechanical Properties of Hemp Fibre Composites. Polymer Composites, 33, 120-128.

[13] Mehta, G., Mohanty, A.K., Drzal, L.T., Kamdem, D.P. and Misra, M. (2006) Effect of Accelerated Weathering on Biocomposites Processed by SMC and Compression Moulding. Journal of Polymers and Environment, 14, 359-368. http://dx.doi.org/10.1007/s10924-006-0029-0

[14] (1994) The Effect of UV Light and Weather on Plastics and Elastomers. Plastics Design Laboratory, New York. 